\title{
Decolorization of Azo Dyes in Dual-Chamber Biocatalyzed electrolysis Systems Seeding with Enriched Inoculum
}

\author{
Dan Cui, Fan-Ying Kong, Bin Liang, Hao-Yi Cheng, Dan Liu, Qian Sun and Ai-Jie Wang*
}

State Key Laboratory of Urban Water Resource and Environment, Harbin Institute of Technology, 202 Haihe Road, Harbin 150090, P. R. China

\begin{abstract}
Azo dyes pollution has attracted a major environmental concern due to their color and toxicity. In this study, we investigated a biocatalyzed electrolysis system (BES) with a bio-cathode seeding with enriched inoculum for the decolorization of a model azo dye, alizarin yellow $R$ (AYR). The bio-cathode was inoculated with AYR autotrophic biodegrading consortium. Batch test results showed that the decolorization efficiency (DE) of $A Y R(100 \mathrm{mg} / \mathrm{L})$ reached to $93.2 \%$ within 58 hours with $0.5 \mathrm{~V}$ power supplied and $\mathrm{NaHCO}_{3}(840 \mathrm{mg} / \mathrm{L})$ as sole carbon source. Lower DEs of $83.5 \%$ and $70.7 \%$ were respectively observed in abiotic cathode BESs and bio-cathode BESs inoculated with mixed sludge. The result indicated that the enriched inoculum had a significant effect on the cathode performance. The azo bond cleavage of AYR resulted in the formation of p-phenylenediamine, p-nitraniline and 5-aminosalicylic acid. The decolorization efficiency was further enhanced under the optimized condition of $\mathrm{pH}(5.2)$, power supplied (0.5V) and initial AYR concentration (100mg/L), reaching up to $99.2 \%$ within 48 hours with the bio-cathode BESs seeding with the enriched inoculum.
\end{abstract}

Keywords: Biocatalyzed Electrolysis Systems (BESs); Decolorization; Azo Dyes; Alizarin Yellow R (AYR); Bio-Cathode

\section{Introduction}

Azo dyes are widely used in textile, dyestuff, food and paper industries. The wastewater containing of azo dyes is a serious threat to environment and health because of its color and toxicity. Azo dyes are characterized by containing one or more azo groups $(-\mathrm{N}=\mathrm{N}-)$, with most of them being xenobiotics and they would result in the decrease of water transmittance, and lead to the destruction of water ecosystems [1]. Dye wastewater is usually treated using physical and chemical processes including of photo degradation [2-5], chemical oxidation [6, 7], membrane processes [8], coagulation and flocculation $[9,10]$ etc. They have advantages in decolorization performance and removal rate. However, they require significant quantities of chemicals and produce notable amounts of sludge, requiring further handling and disposal. The adsorbent used in these processes is difficult to be regenerated and needs further treatment. These drawbacks have greatly limited their scaling-up application. Electrochemical technique is also considered to be a robust method for azo dyes wastewater treatment. But catalysts are reported to be used in both anodes and cathodes, which resulted in high over potentials at both electrodes and accordingly energy consumption $[11,12]$. Azo dyes are resistant to biodegradation under aerobic conditions whereas anaerobic treatment is applied successfully. Anaerobic biological process presents potential advantages in terms of cheap and environmental compatibility but usually is very slow and requires an electron donor to create the necessary reductive conditions $[13,14]$.

Recently, based on the integration of a biological process and electrochemical reduction/oxidation, a novel developed and promising technology named biocatalyzed electrolysis systems (BESs) have been studied extensively to reduce different pollutants [15] such as nitrobenzene [16-18], reductive dehalogenation chloroethenes [19, 20], 2-chlorophenol [21] and iodinated X-ray contrast media [22], decolorization of azo dyes $[1,23]$ with abiotic cathode, pure culture or mixed microbial biocathode. In addition, BESs could also remove pyridine [24], quinoline [25], indole [26], azo dyes [27], antibiotics ceftriaxone sodium and penicillin [28, 29] and 1, 2-dichloroethane [30] from wastewater in the anode chamber or air cathode single chamber MFC with simultaneous generation of electricity.

As reported, BESs have presented a great potential for azo dyes decolorization. Some studies demonstrated the feasibility of using various co-substrates (glucose, acetate sodium or ethanol) for simultaneous decolorization of azo dyes congo red or active brilliant red $\mathrm{X}-3 \mathrm{~B}$ and bioelectricity generation in the proton exchange membrane or microfiltration membrane air-cathode single-chamber MFC [23, 27] and showed that the azo bonds and the naphthyl rings were destroyed to form phenyl derivatives during the congo red biotransformation in the MFC [27]. Abiotically cathodic decolorization of acid orange 7 was studied in dual-chamber BESs, where the process was driven by microbial oxidation of acetate at the anode [1]. An efficient decolorization of the real dye wastewater and bioelectricity generation can be successfully achieved using a MFC with granular carbon bioanode and biocathode [31]. Most studies utilized abiotic cathodes or bio-cathodes inoculated with mixed activated sludge for azo dyes decolorization. Few researches focused on the performance of biocathode BESs seeding with enriched inoculums and the optimization of BESs operation conditions.

This study aims to evaluate the applicability of a bio-cathode biocatalyzed electrolysis system (BES)for the treatment of synthetic azo dyes wastewater in the cathode chamber. This study focused on the improvement of decolorization efficiency through a bio-cathode

*Corresponding author: Ai-Jie Wang, State Key Laboratory of Urban Wate Resource and Environment, Harbin Institute of Technology, 202 Haihe Road, Harbin 150090, P. R. China, Tel. +86-451-86282195, Fax. +86-451-86282195, E-mail:waj0578@hit.edu.cn

Received November 21, 2011; Accepted December 08, 2011; Published December 10, 2011

Citation: Cui D, Kong FY, Liang B, Cheng HY, Liu D, et al. (2011) Decolorization of Azo Dyes in Dual-Chamber Biocatalyzed electrolysis Systems Seeding with Enriched Inoculum. J Environment Analytic Toxicol S3:001. doi:10.4172/2161 0525.S3-001

Copyright: (c) 2011 Cui D, et al. This is an open-access article distributed unde the terms of the Creative Commons Attribution License, which permits unrestricted use, distribution, and reproduction in any medium, provided the original author and source are credited. 
Citation: Cui D, Kong FY, Liang B, Cheng HY, Liu D, et al. (2011) Decolorization of Azo Dyes in Dual-Chamber Biocatalyzed electrolysis Systems Seeding with Enriched Inoculum. J Environment Analytic Toxicol S3:001. doi:10.4172/2161-0525.S3-001

BES seeding with enriched inoculums and optimization of operation conditions, as well as identification of the breakdown products.

\section{Methods and Materials}

\section{Chemicals}

AYR, p-nitraniline and p-phenylenediamine with purity of $98 \%$ were obtained from Aladdin Chemistry Co. Ltd (Shanghai, China). 5 -aminosalicylic acid with purity of $98.5 \%$ and the HPLC grade methanol were obtained from J\&K Scientific Co. Ltd (Shanghai, China) and Sigma-Aldrich Co. Ltd (St. Louis, MO, U.S.A.), respectively.

\section{Bio-electrochemical systems}

The BESs reactor configuration was according to that elsewhere [17]. The reactor was separated by a cation exchange membrane (CEM, Ultrex CMI-700, Membrane International, U.S.) with the working volume of each chamber of $78 \mathrm{~mL}$. Carbon brush with diameter $4.5 \mathrm{~cm}$ and $4 \mathrm{~cm}$ long (TOHOTENAX Co. Ltd.) was used as anode, which had been cultured in the electrode incubator (MFC mode). Carbon cloth $(5 \mathrm{~cm}$ in diameter, E-TEK, U.S.) was used as the cathode. Titanium wire ( $1 \mathrm{~mm}$ in diameter, Baoji LiXing Titanium Group Co., Ltd., China) was pressed onto the carbon cloth to provide good electrical contact and highly conductance. The anode and cathode potentials were measured using an $\mathrm{Ag} / \mathrm{AgCl}$ reference electrode $(+197 \mathrm{mV}$ vs SHE, Shanghai Precision Scientific Instruments Co. Led.). Insulated copper wires were used to connect the circuit with the external resistance of $10 \Omega$ and power was supplied with a DC Power supply. The anode and cathode as well as the reference electrode were connected to a data acquisition unit (Keithley 2700, Keithley Co., Ltd., USA) to record the half-cell voltages and current every ten minutes. The system was sealed carefully to maintain anaerobic condition. All tests were performed at $25^{\circ} \mathrm{C}$

\section{Inoculation and operation}

The anode was inoculated with the anaerobic sludge (wastewater treatment plant in Harbin, China) mixed (v:v=50:50) with the nutrient medium (acetate $0.5 \mathrm{~g} / \mathrm{L}, \mathrm{KCI} 0.13 \mathrm{~g} / \mathrm{L}, \mathrm{NH}_{4} \mathrm{Cl} 0.31 \mathrm{~g} / \mathrm{L}, 50 \mathrm{mM}$ PBS, trace element $0.5 \mathrm{ml} / \mathrm{L}$ and Wolf's vitamin $0.5 \mathrm{ml} / \mathrm{L}$, with $\mathrm{pH}$ of 7.0.). The cathode was inoculated with enriched inoculums mixed $(\mathrm{v}: \mathrm{v}=50: 50)$ with the same nutrient medium as that in the anode but not containing acetate. AYR was continuously added as electron acceptor and $\mathrm{NaHCO}_{3}$ as electron donor. The enriched AYR autotrophic biodegrading consortium used for cathode inoculation was cultured using serum bottles. $10 \mathrm{~mL}$ activated sludge obtained from wastewater treatment plant and $100 \mathrm{~mL}$ nutrient medium containing $50 \mathrm{mg} / \mathrm{L}$ AYR, $840 \mathrm{mg} / \mathrm{L} \mathrm{NaHCO}_{3}$ and $20 \mathrm{~mL} \mathrm{H}_{2}$ were filled into 3 serum bottles and incubated for 7 days at $30^{\circ} \mathrm{C} . \mathrm{H}_{2}$ was spared into the three bottles every 12 hours to prevent oxygen entering the anaerobic bottles. The culture with the highest decolorization efficiency (DE) was transferred to the same medium five times before inoculation.

During the startup period, the enriched bio-cathode BESs operated with $0.5 \mathrm{~V}$ voltage supplied and a high-precision resistor $(10 \Omega)$ in series with it for current measurement. $20 \mathrm{~mL}$ of AYR biodegrading enrichment was centrifuged, and the pellet was mixed with the catholyte and added to the cathode chamber in the initial five cycles. Then the cathodic solution was only replaced by filter-sterilized catholyte $(0.22$ $\mu \mathrm{m})$. All of the solution replacements were performed in an anaerobic glovebox. To avoid acetate depletion in the anode chamber, anolyte was refreshed every time when the catholyte was renewed. After operating four weeks, the closed circuit anode and cathode potentials respectively reached to $-450 \mathrm{mV}$ and $-930 \mathrm{mV}$ vs $\mathrm{Ag} / \mathrm{AgCl}$, indicating the successful startup of BESs. Several parallel control batch experiments were performed under identical conditions: (I) open circuit abiotic cathode BESs (abio-cathode BESs-open); (II) open circuit bio-cathode BESs inoculated with enriched consortium (bio-cathode BESs-open); (III) closed circuit abiotic cathode BESs (abio-cathode BESs-closed); (IV) closed circuit bio-cathode BESs inoculated directly with mixed activated sludge (bio-cathode BESs-mixed sludge).

To investigate the optimum operation conditions, experiments with variable applied voltages $(0.7,0.5$, and $0.3 \mathrm{~V})$, initial AYR concentrations $(50,100,200$, and $300 \mathrm{mg} / \mathrm{L})$ and initial $\mathrm{pH}$ values (5.2, 7.0, and 9.0) were conducted. The $\mathrm{pH}$ was adjusted with $0.1 \mathrm{mM} \mathrm{HCl}$ and $0.1 \mathrm{mM} \mathrm{NaOH}$. Only those results obtained under steady state conditions are reported in this paper.

\section{Analytics and calculations}

Chemical analyses and calculations: Samples taken from the cathode chambers of the BESs were immediately filtered through a $0.22 \mu \mathrm{m}$ filter. The concentration of AYR was measured using a UV/ visible spectrophotometer (Shimadzu UV2550, Japan) at $372 \mathrm{~nm}$. The concentrations of products (p-phenylenediamine, p-nitranilineand 5 -aminosalicylic acid) were measured by a high performance liquid chromatography (HPLC, model e2695, Waters Co., U.S.) equipped with a Water Symmetry C18 column $(5 \mu \mathrm{m} ; 5 \times 150 \mathrm{~mm}$, Waters Co. $)$ at $35^{\circ} \mathrm{C}$ and a UV/visible detector (model-2489 Waters, US) for measurement at $288 \mathrm{~nm}$ and $368 \mathrm{~nm}$ with mobile phase methanol/ $\mathrm{H}_{2} \mathrm{O}$ (containing $0.03 \%$ acetic acid) $(8: 2)$ at a flow rate of $1.0 \mathrm{~mL} / \mathrm{min}$. The retention time of p-phenylenediamine, 5-aminosalicylic acid and p-nitraniline were $2.101 \mathrm{~min}, 3.021 \mathrm{~min}$ and $6.436 \mathrm{~min}$, respectively.

The AYR DE was calculated as follow:

$$
D E=\frac{C_{i n-A Y R}-C_{e f-A Y R}}{C_{i n-A Y R}} \times 100 \%
$$

Where $\mathrm{C}_{\text {in-AYR }}$ is the influent AYR concentration, $\mathrm{mg} / \mathrm{L}, \mathrm{C}_{\text {ef-AYR }}$ is the effluent AYR concentration, $\mathrm{mg} / \mathrm{L}$.

The products formation efficiency $\left(\mathrm{E}_{\mathrm{p}}\right)$ was calculated as follow:

$$
E_{P}=\frac{C_{p} / M_{p}}{\left(C_{i n-A Y R}-C_{e f-A Y R}\right) / 287.23} \times 100 \%
$$

Where $\mathrm{C}_{\mathrm{p}}$ is the concentration of product, $\mathrm{mg} / \mathrm{L} ; \mathrm{M}_{\mathrm{p}}$ is the molar mass of product, $\mathrm{mg} / \mathrm{mmol} ; 287.23$ is the molar mass of AYR, $\mathrm{mg} / \mathrm{mmol}$.

Electrochemical Impedance Spectroscopy (EIS): EIS measurements were carried for the cathodes in a frequency range of $10^{5} \mathrm{~Hz}$ to $0.01 \mathrm{~Hz}$ with an AC signal of $10 \mathrm{mV}$ amplitude using an electrochemical workstation (model-660D, CH Instruments Inc. U.S.) equipped with three-electrode system. Cathode impedance spectra were recorded using the cathode as the working electrode, the anode as the counter electrode and the $\mathrm{Ag} / \mathrm{AgCl}$ reference electrode in the cathode chamber as the reference electrode. The Nyquist plots obtained from the EIS experiments were fitted with ZSIMPWIN software to obtain the polarization resistances.

Scanning Electron Microscopy (SEM): SEM was used to capture images of the carbon cloth surface at different BESs reactors (biocathode BESs-enriched inoculum, bio-cathode BESs-mixed sludge, abiotic cathode BESs) to compare the microorganisms' growth on different cathodes. The electrodes were imaged by SEM (e-LiNE, Raith $\mathrm{GmbH}$, Dortmund, Germany) at $5.0 \mathrm{kV}$. 
Citation: Cui D, Kong FY, Liang B, Cheng HY, Liu D, et al. (2011) Decolorization of Azo Dyes in Dual-Chamber Biocatalyzed electrolysis Systems Seeding with Enriched Inoculum. J Environment Analytic Toxicol S3:001. doi:10.4172/2161-0525.S3-001

\section{Results and Discussion}

\section{AYR Decolorization in the Bio-Cathode BESs Seeding with Enriched Inoculum}

During startup period, the order of AYR DEs within 58 hours was as follow: bio-cathode BESs-enriched inoculum (79.07 \%) > abioticcathode BESs $(68.68 \%)>$ bio-cathode BESs-mixed sludge $(45.12 \%)$ $>$ bio-cathode BESs-open (20.12\%) > abiotic-cathode BESs-open $(3.6$ \%) (Figure1A). In the bio-cathode BESs-enriched inoculum, the AYR DE was significantly enhanced and the startup time was shortened, demonstrating that the enriched autotrophic bacteria could adapt to the BESs circumstance more quickly than that in mixed activated sludge. About $20 \%$ and 3.6\% AYR could be removed in the open circuit bio-cathode BESs and open circuit abiotic-cathode BESs, respectively. The AYR removal may be attributed to the adsorption in the cathode as few products were detected out in the samples taken from the open circuit reactors by HPLC. During the stable period, the AYR DE of biocathode BESs-enriched inoculum reached to $93.2 \%$ within 58 hours, which was higher than that of bio-cathode BESs-mixed sludge (83.07 $\%)$ and abiotic-cathode BESs (70.68 \%) (Figure1B), indicating the performance of bio-cathode BESs was improved compared with that of abiotic-cathode BESs because of the existence of bacteria. The microbial consortium might involve in bio-electrochemical reduction of AYR and take a role on the electron transfer from the cathode to AYR. The enriched autotrophic bio-cathode BESs achieved an even higher AYR $\mathrm{DE}$ as the bacteria at the cathodes were directionally cultured and in favor of AYR reduction and accelerated the electron transfer.

\section{Determination of Microbial Function of the Bio-Cathode}

SEM was used to view the microorganisms on the carbon cloth cathodes of bio-cathode BESs-enriched inoculum, bio-cathode BESsmixed sludge and abiotic-cathode BESs. At the same magnification, there covered with many bacilliform bacteria on the carbon cloth of bio-cathode BESs-enriched inoculum (Figure 2A) and bio-cathode BESs-mixed sludge (Figure 2B), while the carbon cloth of abioticcathode (Figure 2C) was smooth and with no microorganisms attachment. The two kinds of bio-cathodes showed various biofilm morphologies. The bacteria on the bio-cathode-enriched inoculum formed tight microcolony structure, while that on the bio-cathodemixed sludge had a looser biofilm structure. The tight micricolony on the bio-cathode-enriched inoculum might take an important role in the electron transfer from the electrode to AYR to decrease the internal resistance and increase the reaction rate.

Further evidence to support that the enriched inoculums had an effect on internal resistance was gained from the cathode EIS analysis. According to the impedances spectra of two kinds of bio-cathodes, the cathode polarization resistance of bio-cathode BESs-enriched inoculum was $72.7 \Omega$ and that of bio-cathode BESs-mixed sludge was $76.5 \Omega$ (Figure 3 ). They were both much lower than that of abiotic cathode $(744 \Omega)$. The polarization resistance of bio-cathode seeding with enriched inoculum, that is inversely proportional to the ease of electron transfer, was about ten-order of magnitude lower than that of abiotic cathode and a little smaller than that of bio-cathode inoculated with mixed activated sludge. This clearly proved that the enriched AYR decolorization microorganisms significantly reduced the internal resistance and enhanced the kinetics of the electron transfer reactions. It suggested that the enriched microorganisms attached onto the cathode were able to engage in extracellular electron transfer processes with the polarized electrode serving as the electron donor and AYR as electron acceptor.

\section{AYR reduction in the cathode chamber}

The samples taken from the cathode at different hours were detected by UV/visible spectrophotometer. There were two characteristic absorbance peaks at 372 and $265 \mathrm{~nm}$. The latter one that was gradually decreased with the time was the characteristic absorption peak of AYR. Simultaneously, the former peak at $265 \mathrm{~nm}$ gradually increased, indicating the products formation with the azo bond cleavage of AYR. The samples taken from the biocathode-BES-enriched inoculum after 58 hours were detected by HPLC and the products of AYR decolorization were further identified (Figure 4). The main peaks in the effluent with retention time of 2.101,3.021 and 6.436 min match exactly the retention time of p-phenylenediamine, 5-aminosalicylic acid and p-nitraniline, respectively, indicating that these three compounds were the dominant products of AYR decolorization. At the anode, acetate was oxidized by electrochemically active microorganisms to produce protons and electrons, which were transferred to the cathode. At the cathode, the azo bond of AYR was broken combined with proton and electron, resulting in the formation of colorless product of 5-aminosalicylic acid and p-nitraniline. P-nitraniline was further reduced into p-phenylenediamine. However, according to the results

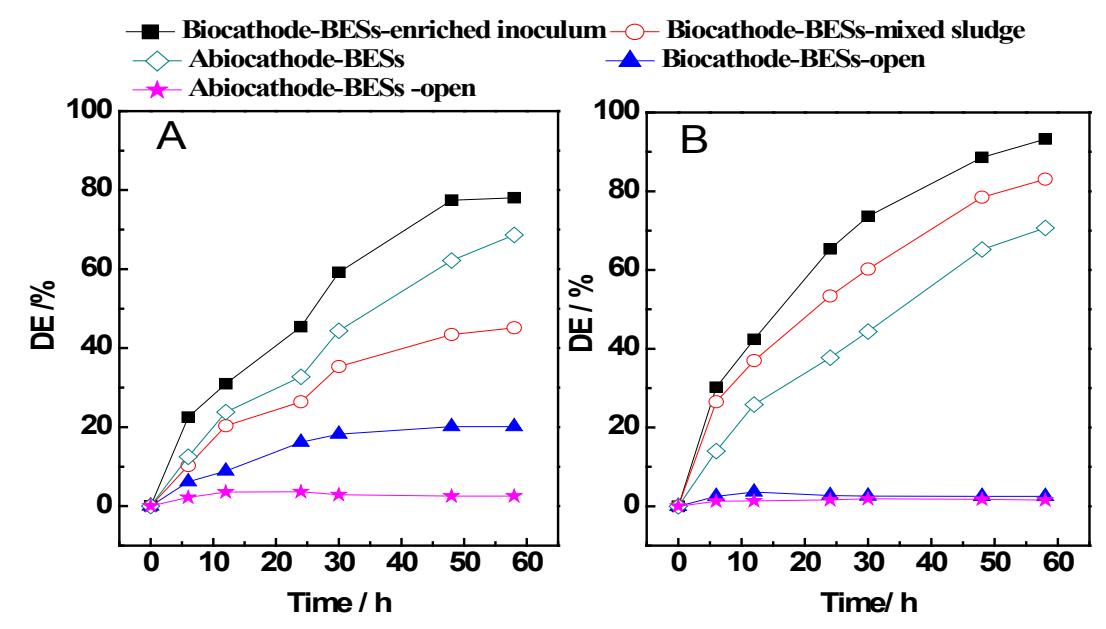

Figure 1: The DE of AYR in different BESs at startup period and stable period. 
Citation: Cui D, Kong FY, Liang B, Cheng HY, Liu D, et al. (2011) Decolorization of Azo Dyes in Dual-Chamber Biocatalyzed electrolysis Systems Seeding with Enriched Inoculum. J Environment Analytic Toxicol S3:001. doi:10.4172/2161-0525.S3-001

(A)

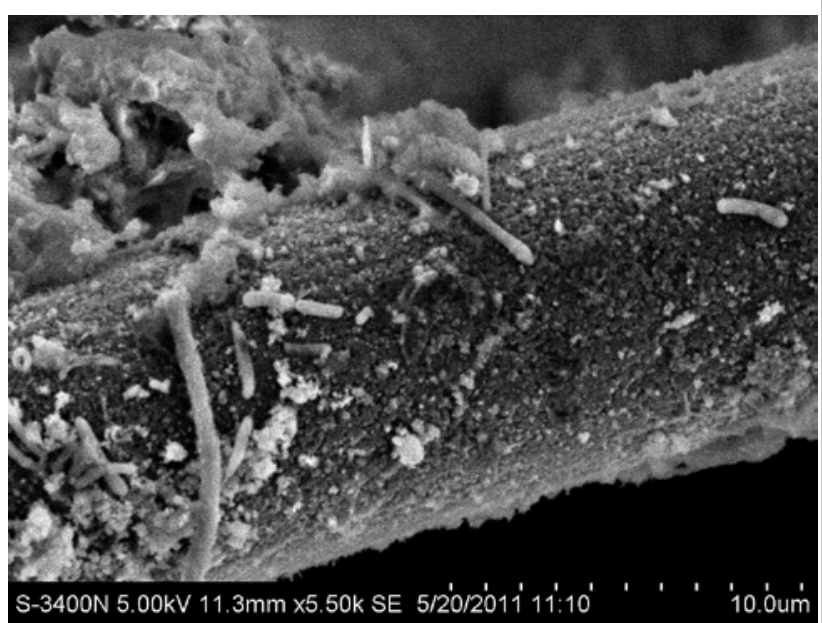

(B)

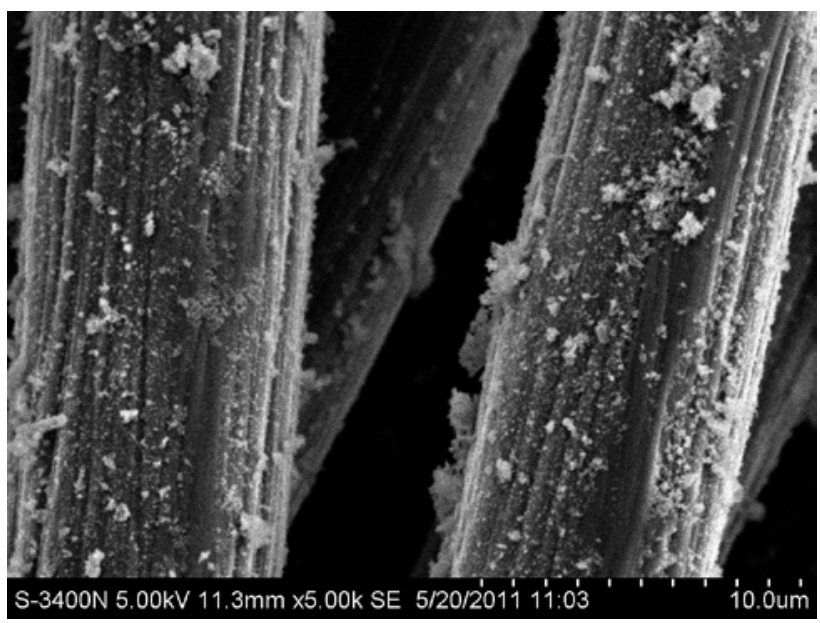

(C)

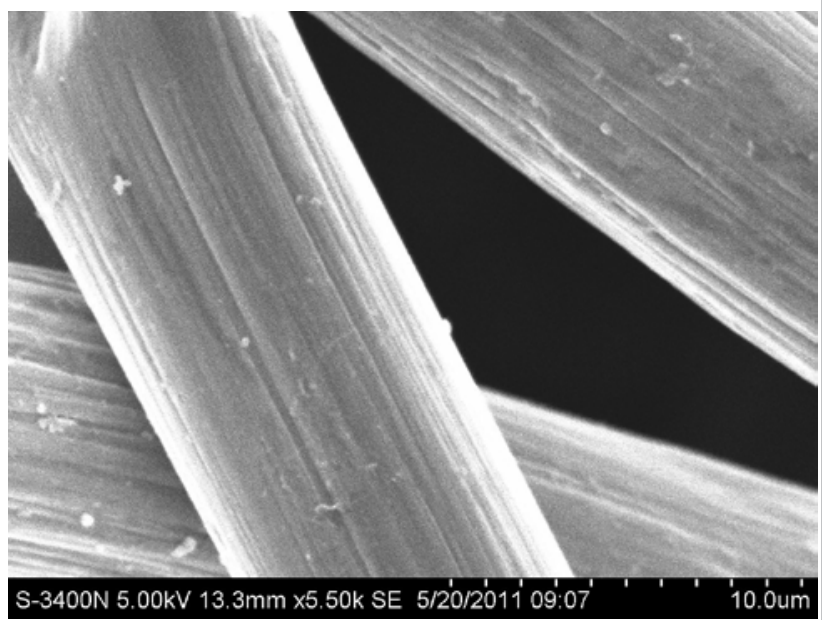

Figure 2: SEM images of $(A)$ bio-cathode-enriched and $(B)$ bio-cathode-mixed sludge and $(C)$ abiotic cathode (with the same cathode electrode of carbon cloth)

shown, p-nitroaniline and 5-aminosalicylic acid were not suitable for evaluating the reduction of AYR due to their unstable behavior in the environment. Therefore, the relatively stable p-phenylenediamine could be used as the quantitative evaluation.

\section{Optimization of operation conditions}

Applied voltage: This study examined the effect of different applied voltages $(0.3,0.5$ and $0.7 \mathrm{~V})$ on AYR DE in the enriched biocathode BESs with initial AYR concentration of $100 \mathrm{mg} / \mathrm{L}$ and $\mathrm{pH}$ of 7.0. As shown in Figure 5A, AYR DE was significantly enhanced with the applied voltage increased from 0.3 to $0.7 \mathrm{~V}$. The AYR DE increased from $78.2 \%$ to $98.1 \%$ within 48 hours. Correspondingly, the current densities increased from 2.14 to $3.16 \mathrm{~A} / \mathrm{m}^{2}$ (data not shown). These results clearly indicated that the applied voltage at the BESs had an important effect on the azo dye DE and current density. With a relatively stable anode potential, a larger applied voltage led to a more negative cathode potential, indicating a more reduced environment for electron transfer from cathode electrode to azo bond for AYR decolorization. This also led to the increase of reaction speed, which contributed to the increase of current as well as current density. However, higher applied voltage will result in more energy consumption and higher cost. In this system, $0.5 \mathrm{~V}$ was enough to ensure the efficient AYR decolorization and stable anode and cathode potentials.

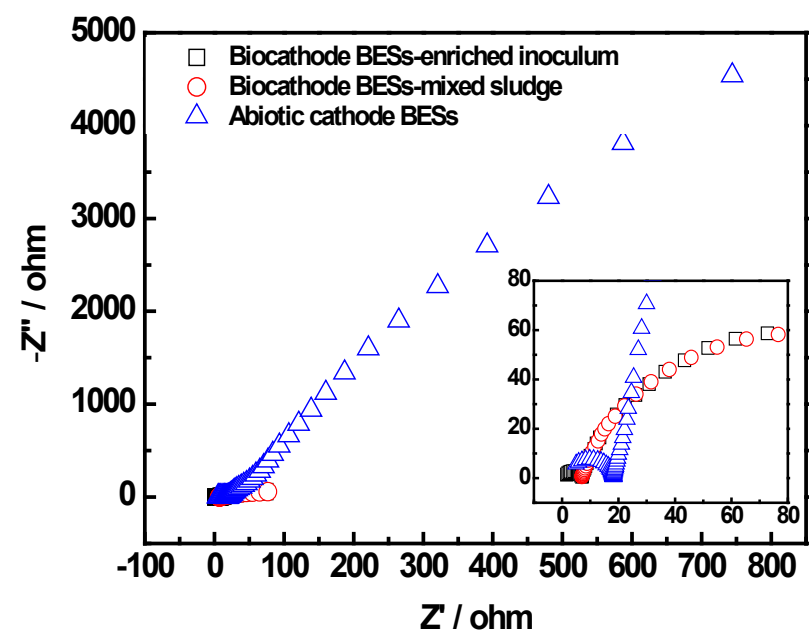

Figure 3: Nyquist plots corresponding to the impedance spectra of cathodes of bio-cathode BESs-enriched, bio-cathode BESs-mixed sludge and abiotic cathode BESs.

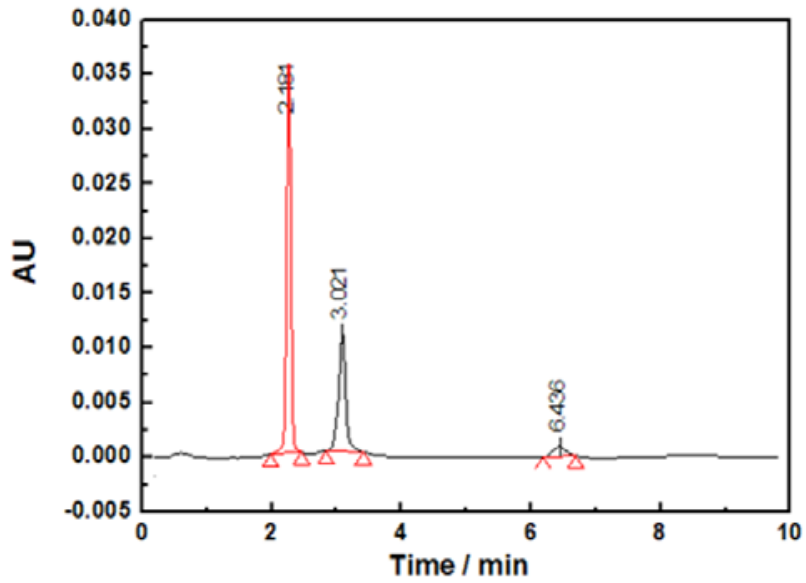

Figure 4: HPLC chromatogram of AYR decolorization products. 
Citation: Cui D, Kong FY, Liang B, Cheng HY, Liu D, et al. (2011) Decolorization of Azo Dyes in Dual-Chamber Biocatalyzed electrolysis Systems Seeding with Enriched Inoculum. J Environment Analytic Toxicol S3:001. doi:10.4172/2161-0525.S3-001

Page 5 of 6
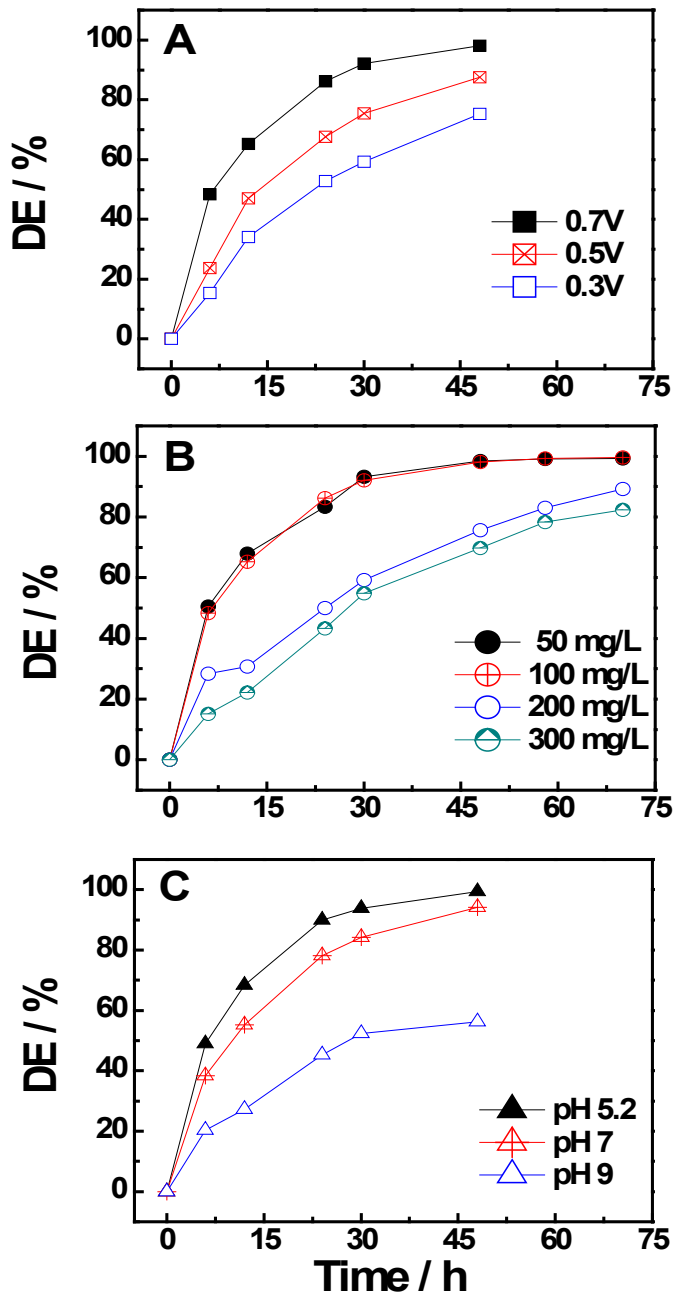

Figure 5: Effect of applied voltage (A), initial AYR concentration (B), and pH (C) on the DE of AYR in BESs

Initial AYR concentration: Figure $5 B$ showed the AYR DE in BESs with different initial AYR concentrations of 50,100, 200, and 300 $\mathrm{mg} / \mathrm{L}$ at the applied voltage of $0.7 \mathrm{~V}$ and $\mathrm{pH}$ of 7.0 . The $\mathrm{DE}$ at the initial AYR concentrations of 50 and $100 \mathrm{mg} / \mathrm{L}$ reached up to $98 \%$ within 48 hours, while it was decreased to $71 \%$ and $69 \%$ when the influent AYR concentration increased to 200 and $300 \mathrm{mg} / \mathrm{L}$, respectively. Correspondingly, the AYR removal rate was $25.5,37.0$ and $53.9 \mathrm{~g} / \mathrm{m}^{3} \cdot \mathrm{d}$ with the initial AYR concentration of 100, 200 and $300 \mathrm{mg} / \mathrm{L}$. It can be noted that the AYR removal rate increased slowly and did not change proportionally to the increase of influent AYR concentration when the initial AYR concentration was higher than $100 \mathrm{mg} / \mathrm{L}$. The reason for this may be due to the anode and cathode reactions. Firstly, higher initial AYR concentration might make some inhibition to the activity of cathodic microorganisms because of its toxicity, which resulted in the slower reaction speed on the cathode. In addition, the AYR reduction in the cathode was driven by the anode oxidation reaction. The capability of electrons supply in the anode was constant, which made a limitation of cathode reaction speed. Thus, the AYR removal rate can not proportionally increase with the increase of initial AYR concentration. The proper initial AYR concentration should be lower than $100 \mathrm{mg} / \mathrm{L}$ to ensure a high DE achieved in this system.
pH: The synthetic AYR wastewater in the cathode was respectively adjusted to 5.2, 7.0 and 9.0 to investigate the effect of $\mathrm{pH}$ on the performance of the enriched bio-cathode BESs. At the AYR concentration of $100 \mathrm{mg} / \mathrm{L}$ and the applied voltage of $0.7 \mathrm{~V}$, with the increase of $\mathrm{pH}$ from 5.2 to 9.0, the AYR DE was decreased from 99.32 $\%$ to $56.3 \%$ within 54 hours (Figure $5 \mathrm{C}$ ). The result indicated that it was very important to avoid $\mathrm{pH}$ increased in the cathode chamber in order to maintain the high microbial activity and AYR DE. As is known, the presence of membrane between anode and cathode chamber would limit the proton transmission rate. Protons and electrons were consumed in an equal ratio in the cathode reaction, thus proton was the limited factor for decolorization if electron was adequate at the applied voltage. Hence, the AYR DE increased with $\mathrm{pH}$ decreased at the cathode. The $\mathrm{pH}$ would increase due to the production of p-phenylenediamine in BESs, which would restrain the microbial survival and enzymatic activity and then affect the azo dyes wastewater treatment. In our system, $50 \mathrm{mM}$ PBS was contained for $\mathrm{pH}$ control as well as $\mathrm{HCl}$ and $\mathrm{NaOH}$ were used for $\mathrm{pH}$ adjustment. The $\mathrm{pH}$ did not change a lot during different operation periods. The AYR DE was improved at the $\mathrm{pH}$ of 5.2 indicating that the protons was enough for AYR decolorizaion with the initial AYR concentration of $100 \mathrm{mg} / \mathrm{L}$ and the microorganism growth did not be inhibited.

Optimum of the operation conditions: Collectively, the optimum operation conditions were investigated in the enriched bio-cathode BESs with the initial AYR concentration of $100 \mathrm{mg} / \mathrm{L}$ at the $\mathrm{pH} 5.2$ and applied voltage of $0.5 \mathrm{~V}$. As shown in Figure5, the whole performance of enriched bio-cathode BESs was greatly improved with AYR DE reached up to $99.23 \%$ at 48 hours, which was higher than the results in the above sections. The formation efficiency of p-phenylenediamine reached to $97.82 \%$, indicating that AYR was efficiently reduced without byproducts accumulation. In addition, the anode and cathode potentials were stable at -378 and $-857 \mathrm{mV}$ vs $\mathrm{Ag} / \mathrm{AgCl}$, which were suitable for anodic microbial growth and cathodic reduction, respectively.

\section{Conclusion}

In this study, the bio-cathode BESs seeding with enriched inoculum were constructed and used for AYR decolorization. The performance of the bio-cathode BESs-enriched inoculum was further improved under the optimum operation conditions (with the initial AYR concentration of $100 \mathrm{mg} / \mathrm{L}$ at the $\mathrm{pH} 5.2$ and applied voltage of $0.5 \mathrm{~V}$ ). The AYR

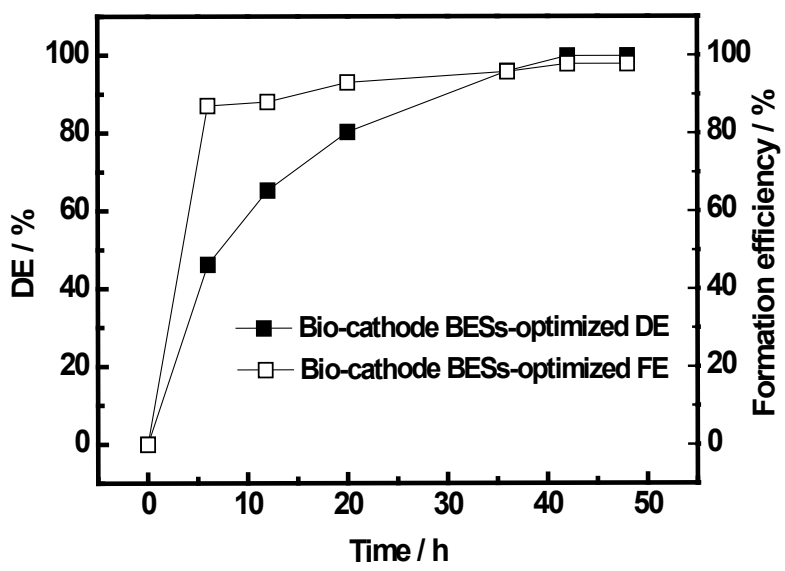

Figure 6: The AYR (DE) and p-phenylenediamine formation efficiency (FE) in the bio-cathode BESs-enriched at the optimum operation conditions. 
Citation: Cui D, Kong FY, Liang B, Cheng HY, Liu D, et al. (2011) Decolorization of Azo Dyes in Dual-Chamber Biocatalyzed electrolysis Systems Seeding with Enriched Inoculum. J Environment Analytic Toxicol S3:001. doi:10.4172/2161-0525.S3-001

DE was as high as $99.23 \%$ companied with the products formation efficiency of $97.82 \%$. Compared with bio-cathode inoculated directly with mixed sludge and abiotic cathode BESs, the enriched autotrophic bio-cathode took a significant role in AYR decolorization in BESs.

\section{Acknowledgments}

This work was supported by National Natural Science Foundation of China (Grant No. 50876024, No. 51078100 and No. 51178140), by National Creative Research Groups Project (Grant No. 51121062), by Heilongjiang Science Foundation for Distinguished Young Scholars (Grant No. JC201003), by National High-Tech Program (No.2009AA064702 and No.2011AA060904), and by State Key Laboratory of Urban Water Resource and Environment (Grant No. 2010DX11 and No. 2008NQ03).

\section{References}

1. Mu Y, Rabaey K, Rozendal RA, Yuan Z, Keller Jr (2009) Decolorization of azo dyes in bioelectrochemical systems. Environ Sci Technol 43: 5137-5143.

2. Kusic H, Juretic D, Natalija K, Vedrana M, Ana Lončarić B (2011) Photo oxidation processes for an azo dye in aqueous media: Modeling of degradation kinetic and ecological parameters evaluation. J Hazard Mater 185: 1558-1568.

3. Wang, X, Jia J, Wang Y (2011). Degradation of C.I. Reactive Red 2 through photocatalysis coupled with water jet cavitation. J Hazard Mater 185: 315-321.

4. Wongkalasin $P$, Chavadej $S$, Sreethawong $T$ (2011) Photocatalytic degradation of mixed azo dyes in aqueous wastewater using mesoporous-assembled $\mathrm{TiO}_{2}$ nanocrystal synthesized by a modified sol-gel process. Colloids and Surfaces A: Physicochemical and Engineering Aspects 384: 519-528.

5. $\mathrm{Mu} \mathrm{Y}, \mathrm{Yu} \mathrm{HQ}$, Zheng JC, Zhang SJ (2004) TiO-mediated photocatalytic degradation of Orange II with the presence of $\mathrm{Mn}^{2+}$ in solution. J Photochem Photobiol 163: 311-316.

6. Türgay O, Ersöz G, Atalay S, Forss J, Welnder U (2011) The treatment of azo dyes found in textile industry wastewater by anaerobic biological method and chemical oxidation. Sep Purif Technol 79: 26-33.

7. Fu L, You SJ, Zhang GQ, Yang FL, Fang XH (2010) Degradation of azo dyes using in-situ Fenton reaction incorporated into $\mathrm{H}_{2} \mathrm{O}_{2}$-producing microbial fuel cell. Chem Eng J 160: 164-169.

8. Konsowa AH, Abd El-Rahman HB, Moustafa MA (2011) Removal of azo dye acid orange 7 using aerobic membrane bioreactor. Alexandria Engineering Journal 50: 117-125.

9. Golab V, Vinder A, Simonic, M (2005) Efficiency of the coagulation/flocculation method for the treatment of dye bath effluent. Dyes Pigm 67: 93-97.

10. Zhu HY, Jiang R, Liang $X$ (2010) Adsorption of an anionic azo dye by chitosan/ kaolin/ [gamma]-Fe2O3 composites. Appl Clay Sci 48: 522-526.

11. del Río Al, Fernández J, Molina J, Bonastre J, Cases F (2011) Electrochemical treatment of a synthetic wastewater containing a sulphonatedazo dye. Determination of naphthalenesulphonic compounds produced as main byproducts. Desalination 273: 428-435.

12. Kariyajjanavar $P$, Jogttappa N, Nayaka YA (2011) Studies on degradation of reactive textile dyes solution by electrochemical method. J Hazard Mater 190: 952-961.

13. Spagni A, Grilli S, Casu S, Mattioli D (2010) Treatment of a simulated textile wastewater containing the azo-dye reactive orange 16 in an anaerobic-biofilm anoxic-aerobic membrane bioreactor. Int Biodeterior Biodegrad 64: 676-681.

14. van der Zee FP, Villaverde S (2005) Combined anaerobic-aerobic treatment of azo dyes - A short review of bioreactor studies. Water Res 39: 1425-1440.

15. Huang L, Cheng S, Chen G (2011) Bioelectrochemicalprocesss for efficien recalcitrant wastes treatment. J Chem Technol Biotechnol 86: 481-491.

16. Mu Y, Rozendal RA, Rabaey K, Keller J (2009) Nitrobenzene removal in bioelectrochemical sytems. Environ Sci Technol 43: 8690-8695.
17. Wang AJ, Cheng HY, Liang B, Ren NQ, Cui D, Lin N. Kim B H, Rabaey K (2011) Efficient reduction of nitrobenzene to aniline with a biocatalyzed cathode. Environ Sci Technol 45:10186-10193.

18. Wang AJ, Cui D, Cheng HY, Guo YQ, Kong FY, Ren NQ, Wu WM (2011) A membrane-free, continuously feeding, single chamber up-flow biocatalyzed electrolysis reactor for nitrobenzene reduction. J. Hazard. Mater Doi:10.1016/j jhazmat.2011.11.034.

19. Lohner ST, Becker D, Mangold KM, Tiehm A (2011) Sequential reductive and oxidative biodegradation of chloroethenes stimulated in a coupled bioelectroprocess. Environ Sci Technol 45:6491-6497.

20. Strycharz SM, Woodard TL, Johnson JP, Nevin KP, Sanford RA, et al. (2008) Graphite electrode as a sole electron donor for reductive dechlorination of tetrachlorethene by Geobacterlovleyi. Appl Environ Microbiol 74: 5943-5947.

21. Strycharz SM, Gannon SM, Boles AR, Franks AE, Nevin KP, et al. (2010) Reductive dechlorination of 2-chlorophenol by Anaeromyxobacterdehalogenans with an electrode serving as the electron donor. Environ Microbiol Rep 2: 289 294.

22. Mu Y, Radjenovic J, Shen JY, Rozendal RA, Rabaey K, et al. (2011) Dehalogenationofiodinated $\mathrm{X}$-ray contrast media in a bioelectrochemical system. Environ Sci Technol 45: 782-788.

23. Sun J, Bi Z, Hou B, Cao YQ, Hu YY (2011) Further treatment of decolorization liquid of azo dye coupled with increased power production using microbial fuel cell equipped with an aerobicbiocathode. Water Res 45: 283-291.

24. Zhang C, Li M, Liu G, Luo H, Zhang R (2009) Pyridine degradation in the microbial fuel cells. J Hazard Mater 172: 465-471.

25. Zhang CP, Liu GL, Zhang RD, Luo HP (2010) Electricity production from and biodegradation of quinoline in the microbial fuel cell. J Environ Sci Heal A 45 250-256.

26. Luo Y, Zhang RD, Liu GL, Li J, Li MC, et al. (2010) Electricity generation from indole and microbial community analysis in the microbial fuel cell. J Hazard Mater 176: 759-764.

27. Cao Y, Hu Y, Sun J, Hou B (2010) Explore various co-substrates fo simultaneous electricitygeneration and Congo red degradation in air-cathode single-chamber microbial fuel cell. Bioelectrochemistry 79: 71-76.

28. Wen $Q$, Kong F, Zheng $H$, Cao D, Ren $Y$, et al. (2011) Electricity generation from syntheticpenicillin wastewater in an air-cathode single chamber microbial fuel cell. Chem Eng J 168:572-576.

29. Wen Q, Kong F, Zheng H, Yin J, Cao D, et al (2011) Simultaneous processes of electricity generation and ceftriaxone sodium degradation in an air-cathode single chamber microbial fuel cell. J Power Sources 196: 2567-2572.

30. Pham H, Boon N, Marzorati M, Verstraete W (2009) Enhanced removal of 1,2-dichloroethane by anodophilic microbial consortia. Water Res 43: 2936 2946.

31. Kanagaraj J, Mandal $A B$ (2011) Combined biodegradation and ozonation for removal of tannins and dyes for the reduction of pollution loads. Environ Sci Pollut Res: 10.1007/s11356-011-0534-0
This article was originally published in a special issue, Environmental Pollutants handled by Editor(s). Dr. Ben-Zhan (Benny) Zhu, China; Dr. Aijie Wang, China 